\title{
Editorial
}

\section{Ants and Their Parasites 2013}

\author{
Jean-Paul Lachaud, ${ }^{1,2}$ Alain Lenoir, ${ }^{3}$ and David P. Hughes ${ }^{4}$ \\ ${ }^{1}$ El Colegio de la Frontera Sur, Departamento de Conservación de la Biodiversidad, Avenida Centenario Km. 5.5, AP 424, \\ 77014 Chetumal, Quintana Roo, Mexico \\ ${ }^{2}$ Centre de Recherches sur la Cognition Animale, CNRS-UMR 5169, Université de Toulouse UPS, 118 route de Narbonne, \\ 31062 Toulouse Cedex 09, France \\ ${ }^{3}$ IRBI, CNRS-UMR 7261, Faculté des Sciences, Université François Rabelais, Parc de Grandmont, 37200 Tours, France \\ ${ }^{4}$ Department of Entomology and Biology, Center for Infectious Disease Dynamics, Penn State University, University Park, \\ PA 16802, USA
}

Correspondence should be addressed to Jean-Paul Lachaud; jlachaud@ecosur.mx

Received 12 June 2013; Accepted 12 June 2013

Copyright (c) 2013 Jean-Paul Lachaud et al. This is an open access article distributed under the Creative Commons Attribution License, which permits unrestricted use, distribution, and reproduction in any medium, provided the original work is properly cited.

Ants, like any animal, are subject to parasitism. However, as they are also superorganisms living in common nests, their parasites experience environments wholly different from those of parasites affecting solitary organisms [1]. The nests of most ant species are relatively stable microhabitats prone to provide both readily available resources and some degree of protection against predators to many organisms. Consequently, ant-parasite (or ant-myrmecophile) associations gather a great deal of diversity ranging from the casual, opportunistic, unspecialized interaction-through temporary protection or sharing of some resources or even predation-, to obligate, specific mutualism that may involve coevolution of both the host and the parasite [2-5].

The first issue of this series examined a wide range of species: viruses, bacteria, fungi, nematodes, silverfishes, flies, butterflies, beetles, spiders, wasps, and ants themselves. However, it could not cover all possible ant parasites. More studies examining their complex interactions from every possible angle, attempting to bring a more global vision of the functioning of such an evolutionary important relationship, are a challenging and fascinating goal. In this second volume, we continued giving specific attention to both the mechanisms used by ant parasites to integrate into their host colony and the way parasite pressure could affect patterns of reproduction and life history in ant hosts. Moreover, considering the increasing pace of losses in biodiversity due to habitat destruction and climate change, we also wanted to reflect the effort towards accurate faunistic surveys of the diversity of the associations involving ants as hosts and the exact nature of these associations.

This volume is divided into two main sections: (1) antparasite interactions and the mechanisms of integration into the host colony, in which both already known and new associations between ants and a diverse fauna including numerous beetle families, phorid and syrphid flies, diapriid, eucharitid and eurytomid wasps, myrmecophilid crickets, spiders, and bacteria are reviewed and/or discussed considering behavioral, taxonomical, phylogenetical, and even conceptual aspects; (2) social parasitism involving ant-ant interactions, in which different interspecific associations between ant species are reviewed, from the most basic forms illustrated by independent plesiobiotic associations to sophisticated, permanent ones found between slave-making ants or inquiline species and their single specialized hosts.

Ant-Parasite Interactions and the Mechanisms of Integration into the Host Colony. Even if we tried to give more importance to the diversity of ant social parasites and the other kinds of myrmecophiles not tackled in the first issue, Coleoptera remains the most documented group among the myrmecophiles and various contributions still deal with beetles in this second issue. Though the first pioneering lists of antassociated beetles by Märkel [6, 7] dealt with European fauna, few faunistic works have focussed on this part of 
the world in the last decades. For such a reason, the sound up-to-date compilation and review of literature-along with some few new data-provided by A. Lapeva-Gjonova on myrmecophilous beetles of Bulgaria, their host specificity, and the nature of their relations with their hosts, is particularly welcome. Apart from resulting in a comprehensive list of 121 myrmecophilous beetle species from 14 families, associated to 22 out of the 170 ant species of Bulgaria, this review brings an opportunity to our community to access some poorly known or difficult to obtain literatures. Due to their specialized behavioral and morphological adaptations, some groups of myrmecophilous beetles are particularly well documented in different regions. However, determining how complete and accurate their taxonomic status is remains an open question. S. Fattorini and colleagues, through a synthesis of the present knowledge of the alpha and beta taxonomy levels of the Paussini group and a modelling of synonym accumulation curves using logistic functions, show that this tribe is taxonomically stable. Relatively few species are expected to be described in the future on morphological basis (but the existence of cryptic species is still possible) and few currently accepted taxa will be recognized to be synonymous. It appears that morphological characters are not fully adequate to resolve infrageneric relationships and that future works using molecular approach are needed along with more accurate survey in poorly studied zones such as Australian and Oriental regions. Since the first attempts by Wasmann [8, 9], various classifications have tried to organize into a hierarchy the diverse myrmecophile habits of Coleoptera. However, the lack of knowledge on the biology of the myrmecophiles is one of the main problems of such classification and has resulted, in many instances, in discrete groups but with overlapping behavioral categories, confusing our knowledge of the real interactions with the host. Moreover, the fact that scientists attribute the same kind of behavior to an insect solely based on morphological similarities is highly problematic. G. Mynhardt discusses the effectivity of such classification systems, and her main goal merely focuses on a declassification and on the fact that we urgently need more in-depth studies in order to know what is really happening biologically before attempting to place beetles or other myrmecophiles into discrete classification schemes.

The lack of knowledge for numerous associations with ants, which can have high implications in their social structure or may be of potential economic interest, is a general problem and numerous studies have tried to fill this gap. Recent discoveries on bacteria [10] show that they are more and more involved in the evolution of their hosts and raise the question of how much do microbes shape animal development? The maternally transmitted bacteria from the genus Wolbachia, for example, represent a widespread, active component in the conflict of interests within ant colonies [11]. Furthermore, phylogenetic analyses have demonstrated that related Wolbachia commonly infect related hosts and that their host associations show a strong pattern of specialization [12]. In the aim of broadly sampling and searching for those groups of potential interest before performing more targeted studies, Kautz and colleagues show how deep sequencing can be used for a broad screening of infectious bacteria. Using both already available data and new data from a large 16S amplicon 454 pyrosequencing to survey ant associated bacteria, they investigate associations of ants with three genera of bacteria (Wolbachia, Spiroplasma, and Asaia). On the base of available data they conclude that phylogeny and geography are not strong determinants of infection rate. In the past decades, a growing set of literatures has focused on other groups of organisms associated with ants and on their possible use as biological control agents against invasive or economically important species (see [13-15]). This is particularly the case for numerous dipteran and hymenopteran parasitoids, most often closely restricted to specific hosts. An overview of taxonomical, biological, and behavioral aspects of the interaction between leaf-cutting ants of the genera Atta and Acromyrmex and the main four genera of phorid flies attacking them is given by P. J. Folgarait. Focussing on the peculiarities of the parasitoids attacking behaviors towards their host and the defensive responses of the ants against the parasitoids, she both suggests some predictive hypothesis related to phorid-ant interactions and proposes priority lines of research to enhance the use of parasitoids in leaf-cutting ant control. Concerning the hymenopteran parasitoids, J. Torréns offers an up-to-date, well-illustrated review of what is known, for Argentina, about the obligatory ant-associated family Eucharitidae, along with valuable new information on ant-host and/or plant-host associations for various of these species. In particular, he reports an interesting example of concurrent parasitism for the ectatommine ant Ectatomma brunneum, which is parasitized by three eucharitid species from three different genera, a case known previously for only one other species of the same ant genus, E. tuberculatum $[15,16]$. Various other groups of dipteran and hymenopteran parasites are associated with ants, but the biology of only a very small fraction is known and, for most species, the real nature of their interactions with ant-hosts remains uncertain. This is typically the case of diapriid-ant relationships for which there has been a lot of speculation. True associations with ants occur only for a fraction of the diapriid species. The paper by M. S. Loiácono and colleagues gives both useful information on type material recently curated in the Museum of La Plata, in Buenos Aires, and an overview of the presence of the ant-associated species in Argentina. It summarizes a lot of the authors past work on diapriid-ant relationships and more specifically some of the very few cases of true ant parasitoidism in this family. Amongst the dipteran, the hoverflies of the syrphid subfamily Microdontinae illustrate another group for which the relationships with ants need more detailed studies. Whereas all of the species of the genus Microdon for which the natural history is known have been found within ant nests or in their immediate vicinity, with their immature stages developing as predators of the ant brood, such relationships are poorly known for the majority of microdontine taxa. Through a review of the 109 published and unpublished records of associations between microdontine flies and ants, M. Reemer provides a phylogenetic evaluation showing that the microdontine taxa found in association with ants occur scattered throughout their phylogenetic tree, suggesting that myrmecophily would 
be a dominant feature of larval biology for all microdontine flies.

As for all the parasites associated with ants, microdontine species need some mechanism preventing aggressiveness from the ants to allow their integration into the host nest. For some species of Microdon, it has been established that the larvae manage to integrate the host colony using chemical mimicry [17] and, in some cases, biosynthesizing cuticular hydrocarbons similar to those of their host [18], a very uncommon mechanism recently demonstrated to occur also in an histerid beetle [19]. However, even when their integration in the ant nest can be secure, the integration process is not necessarily complete and they do not always lure natural enemies like parasitoid wasps which can locate and parasitize their primary host within the ant nest. This is what occurs for the myrmecophilous wasp, Camponotophilus delvarei, as reported by G. Pérez-Lachaud and colleagues who describe, in various nests of the neotropical weaver ant Camponotus sp. aff. textor, the first case of parasitism of a species of microdontine fly by an eurytomid wasp. Due to the very specific habitat where this association was found, the authors stressed the urgent need to improve our understanding of the biology of both microdontine flies and their natural enemies before their natural habitat is lost. T. Komatsu and colleagues report on another case of apparent incomplete integration, showing an unexpected absence of behavioral integration of the specialist myrmecophilous cricket, Myrmecophilus tetramorii, within the colony of their host, Tetramorium tsushimae. As such integration does exist for other specialized congeneric species like M. kubotai, also found in the colonies of T. tsushimae, this suggests that specialization in the genus Myrmecophilus does not necessarily correlate with intimate behavior of the ant-host and that some species can reach high degree of adaptation to a specific host without sophisticated integration cues. In that particular case, the authors conclude that $M$. tetramorii could be specialized to exploit the host by means other than chemical integration. Nevertheless, as noted previously for Microdon larvae, numerous myrmecophiles do mimic the cuticular hydrocarbon pattern of their host to be accepted or use some chemical mechanism to achieve it. The paper by M. Stoeffler and colleagues deals with the exceptional release of monoterpenes by the tergal gland of two extremely rare Lomechusini species of the rove beetle genus Zyras from Germany, for which both the ant host and the nature of the myrmecophilic relationships were not known with certainty. The similarity between these monoterpenes and those present in some ant-attended aphids and aphid honeydew suggests that $Z$. collaris and $Z$. haworthi could achieve acceptance by their putative host, Lasius fuliginosus, mimicking aphid compounds to stimulate more antennation by the ants and no aggression. Moreover, this finding supports recent data on the molecular phylogeny of Lomechusini indicating that the genus Zyras is much more distant from the genus Pella than previously assumed. Apart from chemical mimicry, ant-mimicking through morphological and/or behavioral mechanisms is largely used by numerous arthropods, and in spiders in particular, to deceive their ant associates, a topic already reviewed in the previous volume [20], but still as fascinating as ever. F. S. Ceccarelli tackles it in a complementary way, focussing on the behavioral aspect of ant-associating spiders (in particular for myrmecomorph species which apparently do not use chemical mimicry) that allow them to live close to the ants and to minimize the costs of this potentially lethal association. The central idea is that the existence of such a diversity of species involved in myrmecomorphy inevitably implies that the benefits (essentially the protection against natural enemies, not against the ants themselves) must overweight the costs.

Social Parasitism Involving Ant-Ant Interactions. The amazing diversity of the forms that can take the dependence of an ant species on one or more other free-living ant species is a fascinating topic that has been recently and excellently reviewed by Buschinger [21]. However, reviewing more basic associations without interdependence, like the plesiobiosis, has barely been tackled. O. Kanizsai and colleagues fill this gap through a preliminary review of our current understanding of ant-ant nesting associations consisting in the casual or regular nesting in close vicinity of two ant species. They establish a list of 48 different plesiobiotic species pairs that have been recorded from various habitat types of the Holarctic region and provide a good discussion of the possible reasons for the associations that have been recorded and of their possible role in the formation of other types of interspecific associations like cleptobiosis or lestobiosis. Pointing out the lack of reliable data, this review raises numerous questions that, hopefully, will promote collecting more and better defined data and extend our knowledge to arboreal species and to Tropical and Neotropical regions. More intricately specialized ant-ant relationships, involving permanently parasitizing species depending upon their hosts throughout their lives, have attracted more attention from numerous scientists. For slave-making ants and their hosts, most of the work has been made on Harpagoxenus and Polyergus [21-23], but some groups of species are less well known. This is the case for the four species of the obligate slave-maker genus Rossomyrmex, each one specializing in raiding a specific species of the genus Proformica in a large geographical area. In their review, F. Ruano and colleagues compile all the available data from the Rossomyrmex-Proformica associations and contrast them with observations on other slave-makers, providing a useful comparative overview. In particular, they emphasize the distinctive biological traits of these associations, namely, concerning their reproductive strategy, some characteristics of their raids, and their dispersal abilities. Addressing the problem of the evolutionary potential for host and parasite in two pairs of Rossomyrmex-Proformica associations presenting contrasting ecological characteristics, they interestingly hypothesize that parasite migration would be counter-selected in fragmented habitats because distant dispersal could lead to get away from the distribution area of the potential host colonies. Among the numerous examples of social parasitism, one of the highest degree of biological interdependence between two species of ants is inquilinism where one species acts as a permanent parasite, but without enslaving the host species. In most cases, the parasite queens do not produce a worker caste and coexist with the host 
queens in the host colony [21]. Until now, only one case of inquilinism has been reported within the poneromorph ants [24], involving a facultative polygynous population of the common Neotropical ectatommine ant Ectatomma tuberculatum and miniature queens of the sibling species E. parasiticum. R. Fénéron and colleagues provide an upto-date survey of the biological, genetical, and behavioral data accumulated since the first discovery of E. parasiticum, fourteen years ago [25], and try to shed light on the evolutionary history of the parasitic relationships between both species. The phylogenetical proximity between both species, along with the fact that the parasite queens are clearly discriminated from conspecifics by the host workers and, apparently, are not well integrated into the host colony, suggest a recent sympatric speciation from the host. The authors also emphasize the endangered status of this inquiline species known but from a single, extremely restricted location in Mexico.

Both this special issue and the one before have demonstrated that a great deal of interest still surrounds parasites that live in ant societies. The intersection between collective groups that have long inspired biologists with studies of the organisms that have evolved to break into the fortress of the nest is an exciting field. Because all fields require a solid, but expanding, foundation of detailed biology from which to progress, we rather feel that the contributions gathered here signal a very bright future for studies into ants and their parasites.

\section{Acknowledgments}

The guest editors would like to thank all of the authors who accepted to participate in this second volume of the annual issue "Ants and Their Parasites". Particular thanks are due to the numerous referees who generously helped improving the quality of the papers, making this special issue possible.

\section{Jean-Paul Lachaud Alain Lenoir David P. Hughes}

\section{References}

[1] D. P. Hughes, "Parasites and the superorganism," in Host Manipulation by Parasites, D. P. Hughes, J. Brodeur, and F. Thomas, Eds., pp. 140-154, Oxford University Press, Oxford, UK, 2012.

[2] W. M. Wheeler, Ants, Their Structure, Development and Behavior, The Columbia University Press, New York, NY, USA, 1910.

[3] D. H. Kistner, "The social insects' bestiary," in Social Insects, H. R. Hermann, Ed., vol. 3, pp. 1-244, Academic Press, New York, NY, USA, 1982.

[4] B. Hölldobler and E. O. Wilson, The Ants, Springer, Berlin, Germany, 1990.

[5] P. Schmid-Hempel, "Parasites in social insects," in Monographs in Behavior and Ecology, J. R. Krebs and T. Clutton-Brock, Eds., Princeton University Press, Princeton, NJ, USA, 1998.

[6] F. Märkel, "Beiträge zur Kenntniss der unter Ameisen lebenden, Insekten, Erstes Stück," Germar's Zeitschrift für die Entomologie, vol. 3, pp. 203-225, 1841.
[7] F. Märkel, "Beiträge zur Kenntniss der unter Ameisen lebenden, Insekten, Zweites Stück," Germar's Zeitschrift für die Entomologie, vol. 5, pp. 193-271, 1844.

[8] E. Wasmann, "Vergleichende studien über ameisengäste und termitengäste," Tijdschrift voor Entomologie, vol. 33, pp. 27-96, 1890.

[9] E. Wasmann, Kritisches Verzeichniss der Myrmekophilen und Termitophilen Arthropoden mit Angabe der Lebensweise und mit Beschreibung Neuer Arten, F. L. Dames, Berlin, Germany, 1894.

[10] E. Pennisi, "How do microbes shape animal development?" Science, vol. 340, no. 6137, pp. 1159-1160, 2013.

[11] T. Wenseleers, F. Ito, S. Van Borm, R. Huybrechts, F. Volckaert, and J. Billen, "Widespread occurrence of the micro-organism Wolbachia in ants," Proceedings of the Royal Society B, vol. 265, no. 1404, pp. 1447-1452, 1998.

[12] J. A. Russell, B. Goldman-Huertas, C. S. Moreau et al., "Specialization and geographic isolation among Wolbachia symbionts from ants and lycaenid butterflies," Evolution, vol. 63, no. 3, pp. 624-640, 2009.

[13] D. H. Feener Jr. and B. V. Brown, "Diptera as parasitoids," Annual Review of Entomology, vol. 42, pp. 73-97, 1997.

[14] L. W. Morrison, "Biological control of Solenopsis fire ants by Pseudacteon parasitoids: theory and practice," Psyche, vol. 2012, Article ID 424817, 11 pages, 2012.

[15] J.-P. Lachaud and G. Pérez-Lachaud, "Diversity of species and behavior of hymenopteran parasitoids of ants: a review," Psyche, vol. 2012, Article ID 134746, 24 pages, 2012.

[16] G. Pérez-Lachaud, J. A. López-Méndez, and J.-P. Lachaud, "Eucharitid parasitism of the Neotropical ant Ectatomma tuberculatum: parasitoid co-occurrence, seasonal variation, and multiparasitism," Biotropica, vol. 38, no. 4, pp. 574-576, 2006.

[17] R. W. Howard, R. D. Akre, and W. B. Garnett, "Chemical mimicry in an obligate predator of carpenter ants (Hymenoptera: Formicidae)," Annals of the Entomological Society of America, vol. 83, no. 3, pp. 607-616, 1990.

[18] R. W. Howard, D. W. Stanley-Samuelson, and R. D. Akre, "Biosynthesis and chemical mimicry of cuticular hydrocarbons from the obligate predator, Microdon albicomatus Novak (Diptera: Syrphidae) and its ant prey, Myrmica incompleta Provancher (Hymenoptera: Formicidae)," Journal of the Kansas Entomological Society, vol. 63, no. 3, pp. 437-443, 1990.

[19] A. Lenoir, Q. Chalon, A. Carvajal et al., "Chemical integration of myrmecophilous guests in Aphaenogaster ant nests," Psyche, vol. 2012, Article ID 840860, 12 pages, 2012.

[20] P. E. Cushing, "Spider-ant associations: an updated review of myrmecomorphy, myrmecophily, and myrmecophagy in spiders," Psyche, vol. 2012, Article ID 151989, 23 pages, 2012.

[21] A. Buschinger, "Social parasitism among ants: a review (Hymenoptera: Formicidae)," Myrmecological News, vol. 12, pp. 219-235, 2009.

[22] P. D'Ettorre and J. Heinze, "Sociobiology of slave-making ants," Acta Ethologica, vol. 3, no. 2, pp. 67-82, 2001.

[23] A. Lenoir, P. D’Ettorre, C. Errard, and A. Hefetz, "Chemical ecology and social parasitism in ants," Annual Review of Entomology, vol. 46, pp. 573-599, 2001.

[24] R. M. Feitosa, R. R. Hora, J. H. C. Delabie, J. Valenzuela, and D. Fresneau, "A new social parasite in the ant genus Ectatomma F. Smith (Hymenoptera, Formicidae, Ectatomminae)," Zootaxa, no. 1713 , pp. 47-52, 2008. 
[25] R. R. da Hora, R. Fénéron, J. Valenzuela, M. E. Favila, and D. Fresneau, "Queen-size dimorphism in the ant Ectatomma tuberculatum (Hymenoptera: Formicidae: Ponerinae)," Sociobiology, vol. 38, no. 3A, pp. 407-420, 2001. 

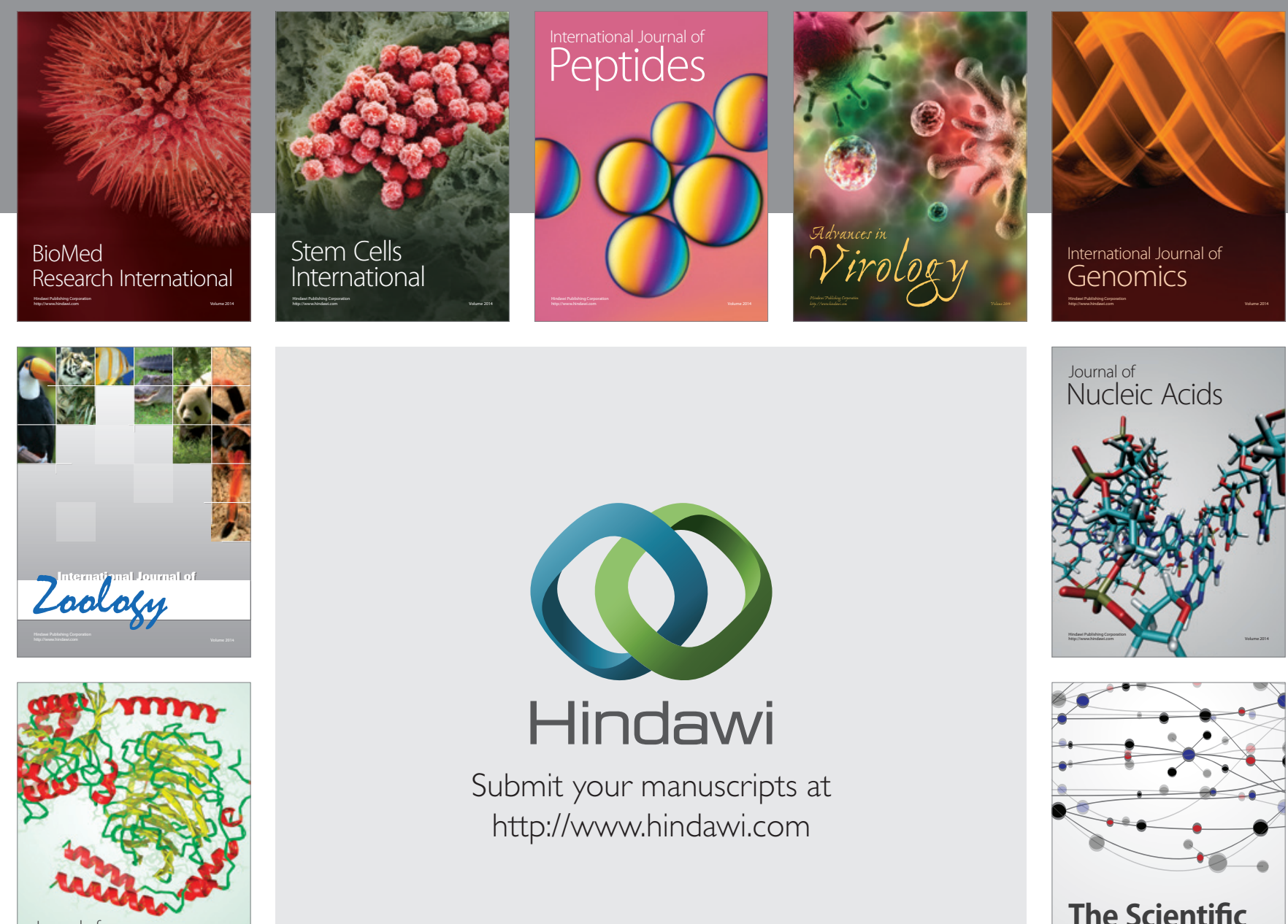

Submit your manuscripts at

http://www.hindawi.com

Journal of
Signal Transduction
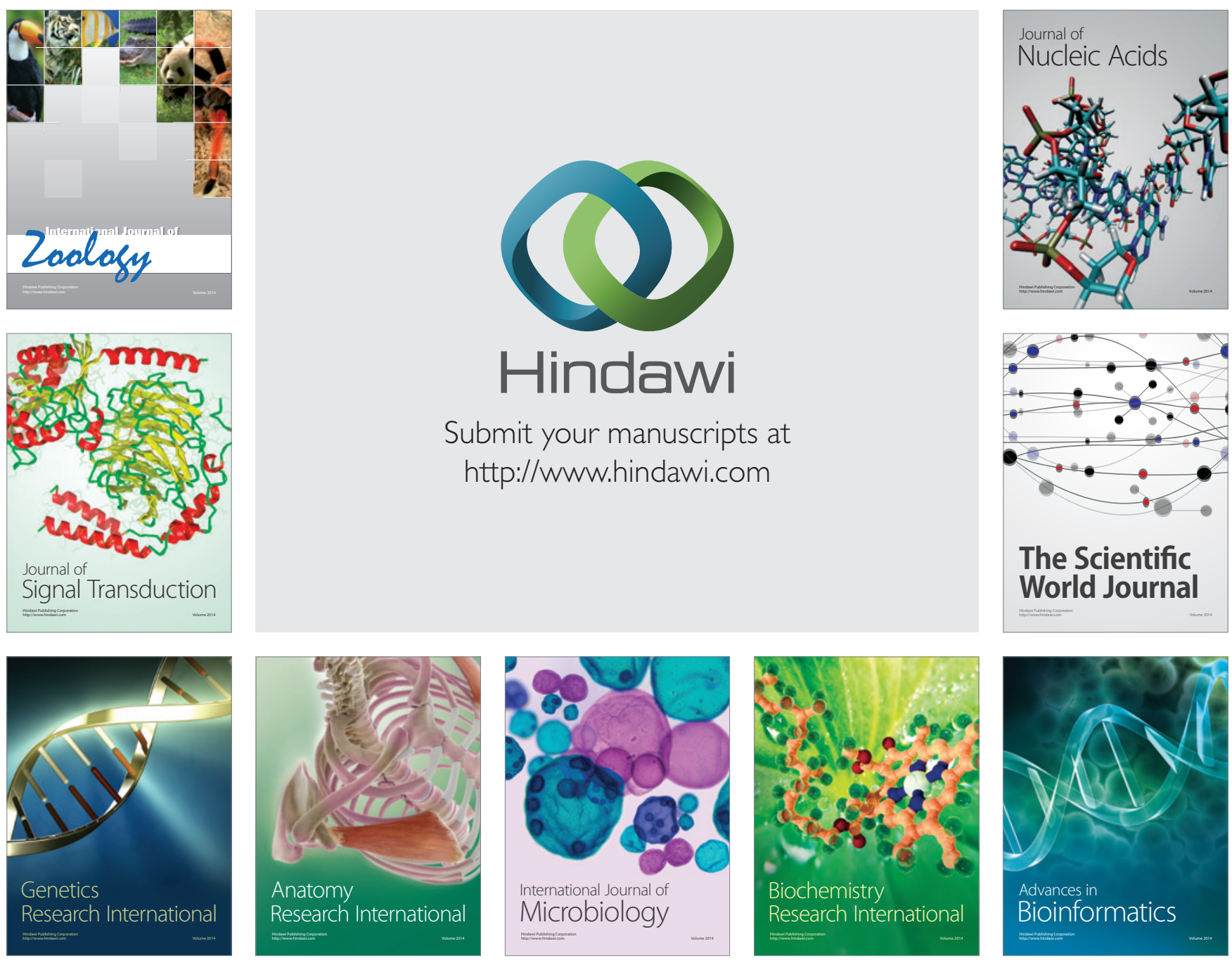

The Scientific World Journal
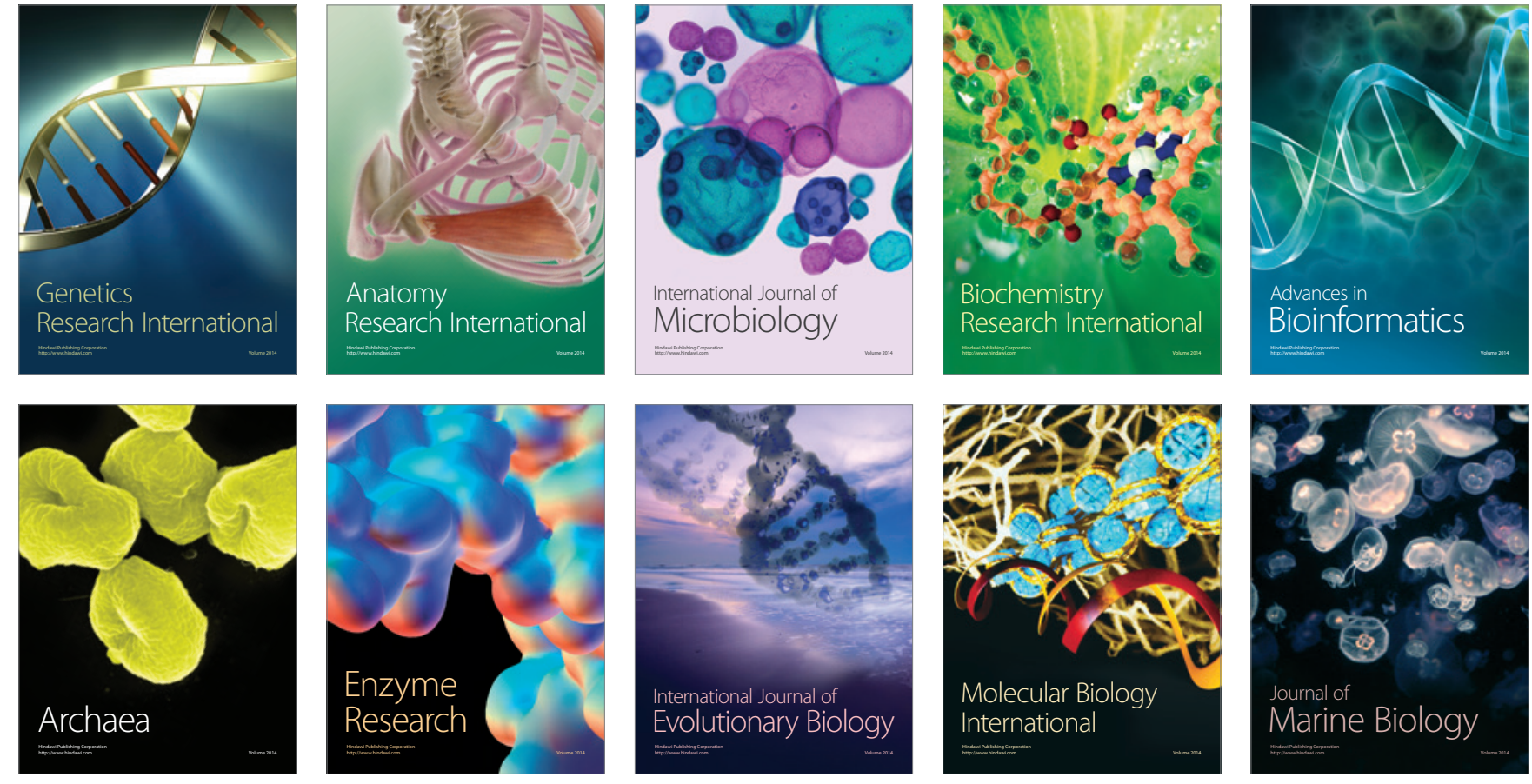